Wenn Kellner endlich meine Resultate als im Widerspruch mit den älteren Forsehern - v. Knieriem usw. - bezeichnet, so sieht er nicht, dass meine durchaus andere Art der Versuchsanstellung zu den abweichenden Resultaten führen musste, und ich verweise der Kürze wegen auf die Arbeiten selbst.

Meine analytischen Befunde sind Mittelzahlen aus mindestens zwei gut übereinstimmenden Analysen, und wir (zootechnisches Institut) benutzen zum Einstellen unserer Titerlösung keine rätselhaften Kontrollsubstanzen, sondern gehen stets von der direkten Säurebestimmung aus.

\title{
Bemerkung \\ zu dem vorangehenden Aufsatz des Herrn Dr. Max Müller.
}

Vom

\section{Herausgeber.}

Nachdem beiden Parteien hinreichende Gelegenheit gegeben war, ihre Ansichten zu verfechten, erkläre ich den Streit in diesem Archive für abgeschlossen. 